\title{
AN ALTERNATE SOURCE OF ENERGY: HYDROGEN FUEL CELLS
}

\section{DEBAJIT MOHAPATRA* \& SASWAT BHUYAN}

ITER, Siksha 'O'Anusandhan Deemed to be University, Bhubaneswar, Odisha, India

\section{ABSTRACT}

Aim of this paper is to study the use of alternate source of energy: hydrogen fuel cells. Power devices are the rising innovation and they are going to control the earth since it is an inexhaustible wellspring of vitality, it has high effectiveness, and it don't hurt nature and a lot more factors. A fuel cell is a gadget which utilizes hydrogen and oxygen to create power by the procedure of electrochemical procedure. A solitary power device comprise of two slender terminal Anode for the most part zinc and Cathode for the most part copper. At the point when the hydrogen and oxygen isn't there, water is utilized to create power by energy units. As we realize that water on electrolysis give hydrogen gas and oxygen. So this strategy is utilized in sun powered energy unit. As indicated by applications and request power modules can be of various kinds, measure and so on. They are conservative in size. Inquiries about are proceeding to enhance the energy components in term of effectiveness, control proportion, unwavering quality and so forth. Presently day energy units are utilized in cars, space makes, remote satellite and so on.

KEYWORDS: Hydrogen, Fuel, Cells \& Energy

Received: Apr 17, 2019; Accepted: May 07, 2019; Published: Jun 12, 2019; Paper Id.: IJMPERDJUN2019175

\section{INTRODUCTION}

Fuel cell is only an electrochemical gadget which convert concoction vitality of a fuel into electrical vitality. It isn't care for customary cell or batteries since it really does not store any vitality. In power module power is delivered by responding the fills (hydrogen and oxygen), the powers consolidates together and give power and side-effects (water)[1].

It was found by German Scientist G H Shoenbein in 1839, while he was probing electrolysis. As we realize that electrolysis is a procedure of passing power into water to part it into oxygen and hydrogen[2]. He saw that its invert is likewise obvious i.e when hydrogen and oxygen join together, power will deliver.

Hydrogen is being utilized as fuel in expanding quantities of today's engine vehicles which are growing locally and globally, with the objective to decrease carbon dioxide outflows. The National Aeronautics and Space Agency (NASA) have been utilizing hydrogen as fuel in their space transports since the 1950's. The market is likewise creating for transports, material dealing with hardware, ground bolster gear, medium and rock solid vehicles, and stationary applications [3]. These applications will radiate zero waste, and just discharges water vapour over into the air.

The paper will discuss about how hydrogen is a fantastic asset of vitality without all the waste related with traditional fills[4]. First the paper will talk about techniques for delivering hydrogen to be utilized in a few application and how they can be put away. In addition, a short exchange on how put away hydrogen, otherwise called hydrogen energy units, is utilized to give power to control vehicles. At long last, a few points of the 
favourable circumstances and weaknesses of using hydrogen for vitality will be referenced[5].

\section{Advantages Over Conventional Batteries}

- Zero emission - Fuel cell do not cause any pollution.

- Very less maintenance - There are very few moving parts hence it requires very less maintenance.

- $\quad$ Available in different sizes.

- Its by-product are water and heat so it can be utilize in different application.

\section{Working Principle}

A fuel cell is a device which uses hydrogen and oxygen to produce electricity by the process of electrochemical process[6].

A single fuel cell consist of two thin electrode Anode generally zinc and Cathode generally copper.
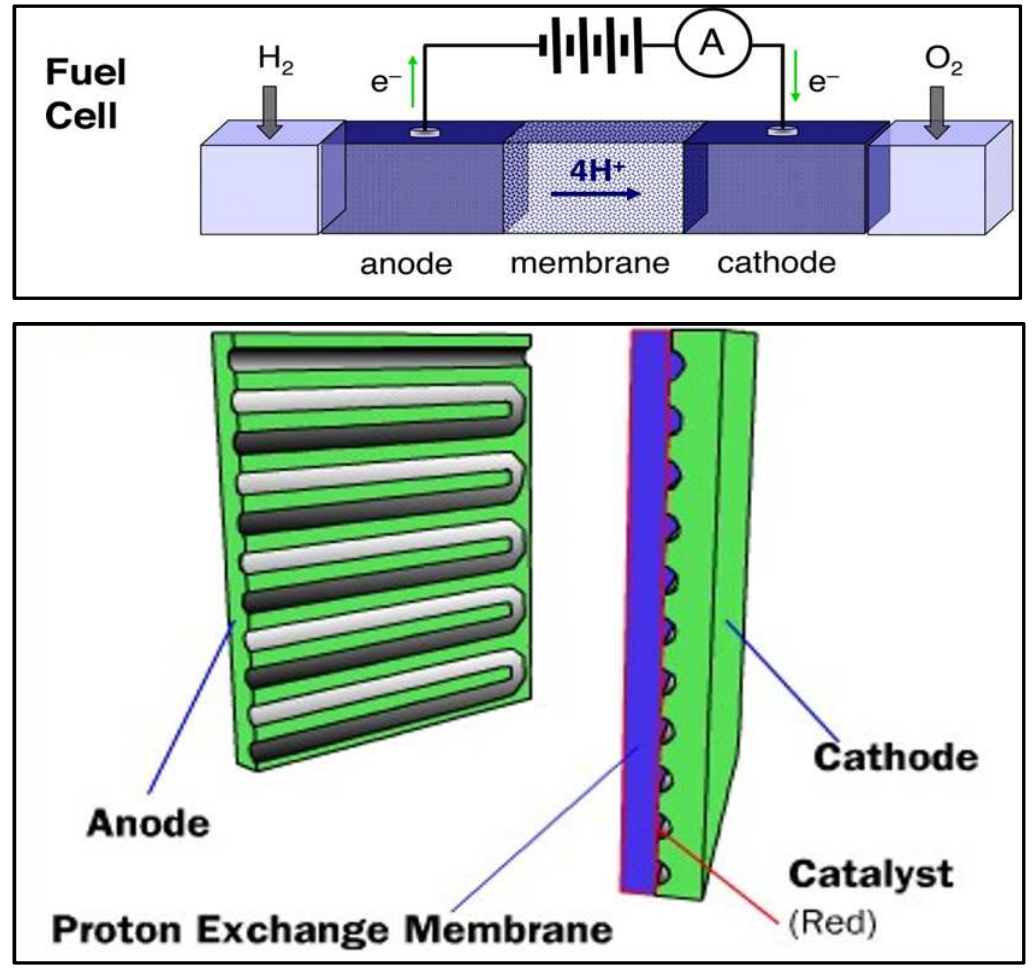

Figure 1

\section{Sandwich Like Structure of a Fuel Cell}

Hydrogen fuel is benefited from anode and oxygen is benefited from cathode and both terminal are isolated by PEM (Proton Exchange Membrane).

Platinum Powder Catalyst is stored on the PEM to expand the speed of the response. At the point when the hydrogen molecule come into contact with impetus it breaks into hydrogen's adversely charged electron and decidedly charged proton[7].

In PEM just proton or emphatically charged particles can travel so the hydrogen proton go through PEM though 
the electron through the terminal travel into circuit. This development of electrons is power. Presently the electron scopes to cathode and it responds with oxygen to shape O2- Presently $\mathrm{H}+$ and O2-consolidate with one another to shape water. As it is an exothermic procedure, heat is additionally discharge as side-effect[8].

\section{Solar Fuel Cell}

At the point when the hydrogen and oxygen isn't there, water is utilized to create power by energy units. As we realize that water on electrolysis give hydrogen gas and oxygen. So this strategy is utilized in sunlight based power module. Sunlight based power help in electrolysis process since utilizing some other vitality is anything but a decent choice on the grounds that sun based vitality is free vitality and alternate procedures are same as of traditional hydrogen energy components[9][10].

\section{Working}

- Solar panel produce electricity.

- This electricity is used in electrolysis and hydrogen and oxygen from water breaks.

- The hydrogen after coming into contact with catalyst converted into hydrogen ion and free electron.

- The electron travel through circuit and react with oxygen into other part of the cell.

- At this stage electricity is produce.

- Oxygen gain 2 electrons.

- Now hydrogen ion passes through PEM and react with oxygen to produce water.

- The reaction continuous as the fuel is available.

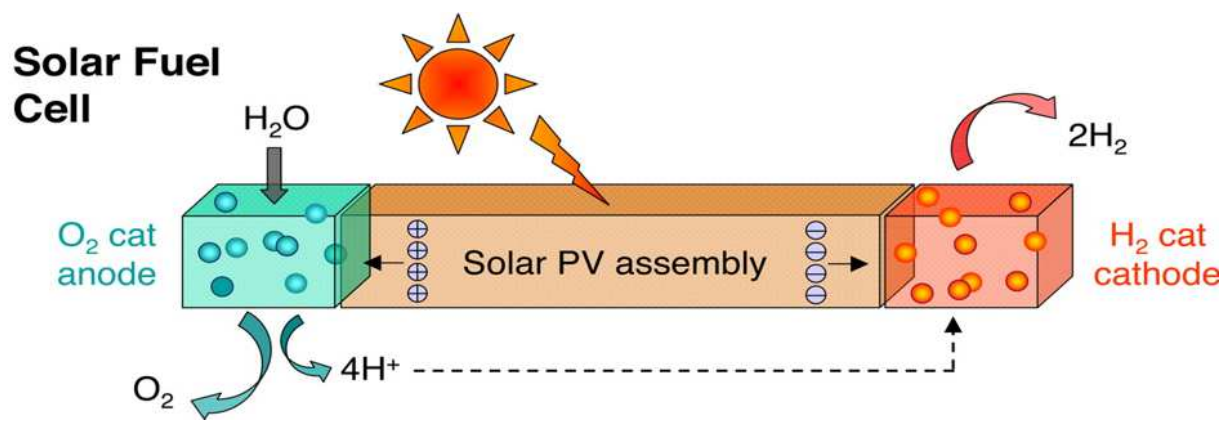

Figure 2

\section{Type of Fuel Cells}

Fuel cells are generally classified into two parts:

- $\quad$ Type of electrolyte

- $\quad$ Type of fuel used

\section{Based on Type of Electrolyte}

a) Alkaline Fuel cell (AFC) 
b) Phosphoric Acid Fuel cell (PAFC)

c) Polymer Electrolytic Membrane Fuel Cell (PEMFC)

i. Solid Polymer Fuel Cell (SPFC) and

ii. Proton Exchange Membrane Fuel cell (PEMFC)

d) Molten Carbonate Fuel Cell (MCFC)

e) Solid Oxide Fuel Cell (SOFC)

\section{Based on Type of Fuel Used}

a) Hydrogen (pure)-Oxygen (pure) fuel cell

b) Hydrogen rich gas-air fuel cell

c) Ammonia -air fuel cell

d) Synthesis gas- air fuel cell

e) Hydro carbon (gas)- air fuel cell

\section{Applications of Fuel Cells}

- In automobiles

- In space craft

- In remote weather forecast satellite

- Portable power generation

- Static power generation

- Can be used for domestic power source

- Can be used in locomotives in future

\section{CONCLUSIONS}

Energy component is certifiably not a typical innovation yet so it is extravagant. Parcel of explores were proceeding to enhance it and to make it accessible for standard individual. On the off chance that it got effective, at that point the energy components will be utilized broadly due to its high productivity, high power proportion, and furthermore it don't bring about any contamination. Because of these components the power module must be given more need than some other wellspring of vitality.

In spite of the fact that there are organizations like Toyota that are executing hydrogen power modules in their future age of vehicles, the procedure still needs further research to guarantee manageability and unwavering quality to give shoppers motivation to move far from fossil-filled vehicles. Moreover, California has begun to give hydrogen stations accessible to vehicles utilizing hydrogen energy components to energize, much like electric autos revive stations.

If hydrogen, in blend with other sustainable power sources, are actualized into individuals' day by day lives and are turned out to be dependable; carbon discharges will lessen significantly. This can result, in the fix of the ozone layer, cleaner air, and the prosperity of our planet. All things considered, a superior spot will be left for who and what is to come. 


\section{REFERENCES}

1. Y. Li, B. Yang, L. Yan, and W. Gao, "Neural network modeling of biomass gasification for hydrogen production," Energy Sources Part A-Recovery Util. Environ. Eff., vol. 41, no. 11, pp. 1336-1343, Jun. 2019.

2. P. Colomban, "Proton conductors and their applications: A tentative historical overview of the early researches," Solid State Ionics, vol. 334, pp. 125-144, Jun. 2019.

3. B. Budde and K. Konrad, "Tentative governing of fuel cell innovation in a dynamic network of expectations," Res. Policy, vol. 48, no. 5, pp. 1098-1112, Jun. 2019.

4. C. Huang et al., "Ce0.6Zr0.3Y0.1O2 solid solutions-supported Ni-Co bimetal nanocatalysts for NH3 decomposition,” Appl. Surf. Sci., vol. 478, pp. 708-716, Jun. 2019.

5. Majeed, M. S., Hamad, T. K., \& Hashim, E. Zno Nanoparticle Synthesis Using Nd: Yag Laser For Increasing Hydrogen Fuel Cell Performance.

6. L. Gong, Q. Duan, J. Sun, and V. Molkov, "Similitude analysis and critical conditions for spontaneous ignition of hydrogen release into the atmosphere through a tube," FUEL, vol. 245, pp. 413-419, Jun. 2019.

7. A. S. Tremsin, T. Shinohara, K. Oikawa, J. Li, and P. J. M. Monteiro, "Non-destructive mapping of water distribution through white-beam and energy-resolved neutron imaging," Nucl. Instruments Methods Phys. Res. Sect. A-Accelerators Spectrometers Detect. Assoc. Equip., vol. 927, pp. 174-183, May 2019.

8. Y. Qian, L. Huang, P. Zhou, F. Tian, and G. Li Puma, "Reduction of Cu(II) and simultaneous production of acetate from inorganic carbon by Serratia Marcescens biofilms and plankton cells in microbial electrosynthesis systems,” Sci. Total Environ., vol. 666, pp. 114-125, May 2019.

9. M. M. Mian, G. Liu, and B. Fu, "Conversion of sewage sludge into environmental catalyst and microbial fuel cell electrode material,” Sci. Total Environ., vol. 666, pp. 525-539, May 2019.

10. Krishnamoorthi, S., Prabhahar, M., Kumar, M. S., \& Sendilvelan, S. (2018). Yield Characteristic of Biodiesel Derived From Used Vegetable Oil Methyl Ester (UVOME) Blended With Diesel, in the Presence of Sodium Hydroxide (NAOH) and Potassium Hydroxide (KOH) Catalyst, As Alternative Fuel for Diesel Engines. International Journal of Mechanical and Production Engineering Research and Development (IJMPERD), 8(1), 9-16.

11. R. Zhang, M. Peng, L. Ling, and B. Wang, "PdIn intermetallic material with isolated single-atom Pd sites - A promising catalyst for direct formic acid fuel cell,” Chem. Eng. Sci., vol. 199, pp. 64-78, May 2019.

12. S. Siracusano et al., "Chemically stabilised extruded and recast short side chain Aquivion $(R)$ proton exchange membranes for high current density operation in water electrolysis,” J. Memb. Sci., vol. 578, pp. 136-148, May 2019. 
